\title{
Combined effects of hyperphosphatemia and hyperglycemia on the calcification of cultured human aortic smooth muscle cells
}

\author{
PING WANG ${ }^{1 *}$, PING ZHOU $^{2 *}$, WANGSHAN CHEN ${ }^{1}$ and DAN PENG ${ }^{3}$ \\ ${ }^{1}$ Nephrology Department, The First People's Hospital of Jingmen, Jingmen, Hubei 448000; \\ ${ }^{2}$ Gastrointestinal Surgery Department, The Central Hospital of Hengyang, Hengyang, Hunan 421001; \\ ${ }^{3}$ Neonatology Department, The First People's Hospital of Jingmen, Jingmen, Hubei 448000, P.R. China
}

Received April 18, 2018; Accepted November 11, 2018

DOI: $10.3892 /$ etm.2018.7024

\begin{abstract}
Vascular calcification (VC) is common in patients with diabetes and/or chronic kidney disease (CKD). It is strongly associated with cardiovascular morbidity and mortality. Hyperphosphatemia caused by CKD induces the transformation of vascular smooth muscle cells (VSMCs) into chondrocytes or osteoblast-like cells. Hyperglycemia may also accelerate VC. However, the exact mechanisms of this remain unclear. The effects of simultaneous hyperphosphatemia and hyperglycemia require investigation. CKD rat models are typically used to study $\mathrm{VC}$, which are far removed from the clinical situations of patients with CKD. The present study cultured human aortic smooth muscle cells (HASMCs) in normal, hyperphosphatemic and/or hyperglycemic conditions for 14 days. Alizarin red staining, calcification content, VSMC differentiation marker gene expression, phenotypic osteoblast gene expression and type III sodium-dependent phosphate cotransporter-1 (Pit-1) protein expression was examined. Hyperphosphatemia and hyperglycemia had combined effects in promoting calcification, phenotypic transition and Pit-1 expression in cultured HASMCs. In the present study, the combined effects of hyperphosphatemia and hyperglycemia on the calcification and phenotypic transition of HASMCs were demonstrated. Hyperphosphatemia combined with hyperglycemia medium should be considered an appropriate experimental model to study VC in diabetic kidney disease (DKD). Pit-1 should be considered as a promising index of $\mathrm{VC}$.
\end{abstract}

Correspondence to: Dr Dan Peng, Neonatology Department, The First People's Hospital of Jingmen, 168 Xiangshan Avenue, Jingmen, Hubei 448000, P.R. China

E-mail: 34298306@qq.com

*Contributed equally

Key words: vascular calcification, human aortic smooth muscle cell, hyperphosphatemia, hyperglycemia, type III sodium-dependent phosphate cotransporter-1

\section{Introduction}

Vascular calcification (VC) is a common event in patients with diabetes and/or chronic kidney disease (CKD) $(1,2)$. It is strongly associated with cardiovascular morbidity and mortality $(3,4)$. Previous studies have revealed that hyperphosphatemia caused by CKD triggers the transformation of vascular smooth muscle cells (VSMCs) into chondrocytes or osteoblast-like cells, and induces medial calcification deposits (5-7). It has also been demonstrated that hyperglycemia induces VC $(8,9)$. The expression of VSMC differentiation marker genes, including smooth muscle $22 \alpha$ (SM22 $\alpha$ ) and smooth muscle $\alpha$-actin (SM $\alpha$-actin), decrease in smooth muscle cell phenotypic transition (10). Expression of the phenotypic osteoblast gene, runt-related transcription factor 2 (Runx2), also known as core binding factor alpha-1, is increased in VC $(11,12)$. Phosphate transport into cells is primarily mediated by sodium-phosphate $(\mathrm{NaPi})$ cotransporters, of which there are 3 types. Type III sodium-dependent phosphate cotransporter-1 (Pit-1) is the predominant NaPi cotransporter in human VSMCs (13). It has been identified as a pivotal transporter in phosphate-induced VSMC calcification. PiT-1 may promote vascular calcification via modulation of anti-calcification proteins (such as matrix Gla protein) or modification of kinases that phosphorylate secreted matrix proteins (such as osteopontin) (14). Pit-1 has been a focus of previous $\mathrm{VC}$ research, and its regulation serves a significant role in the pathogenesis of VC $(15,16)$. However, the exact mechanisms of $\mathrm{VC}$ remain unclear.

Two experimental CKD rat models are typically used to research VC: An adenine-induced CKD model and a partial nephrectomy model. However, these are not the predominant causes of CKD in patients $(17,18)$. Research into the interactions between hyperphosphatemia and hyperglycemia in VC and the underlying mechanisms is limited. In the present study, the effects of hyperphosphatemia and hyperglycemia on the phenotypic transition and calcification of cultured human aortic smooth muscle cells (HASMCs) were investigated, and the associated mechanisms were examined.

\section{Materials and methods}

Cell culture and calcification model.HASMCs were purchased from Procell Life Science and Technology Co., Ltd. (Wuhan, 
China). Cells were cultured in Dulbecco's modified Eagle's medium (DMEM; Hyclone; GE Healthcare Life Sciences, Logan, UT, USA) with $10 \%$ (v/v) fetal bovine serum (FBS; Hyclone; GE Healthcare Life Sciences, Logan, UT, USA) and $1 \%$ streptomycin/penicillin in $5 \%(\mathrm{v} / \mathrm{v}) \mathrm{CO}_{2}$ at $37^{\circ} \mathrm{C}$ in a humidified atmosphere. Cells at passages 4-6 were used for further experimentation. When $80 \%$ confluence was reached, cells were incubated in calcifying media containing $2.5 \mathrm{mM}$ $\mathrm{Pi}$ (inorganic phosphorus) and/or $30 \mathrm{mM}$ glucose for up to 14 days to induce calcification. Medium was replaced every 3 days. $\mathrm{Na}_{2} \mathrm{HPO}_{4} \cdot 12 \mathrm{H}_{2} \mathrm{O}, \mathrm{NaH}_{2} \mathrm{PO}_{4} \cdot 2 \mathrm{H}_{2} \mathrm{O}$ and/or glucose were added to the serum-supplemented DMEM to create various high phosphate and glucose environments, according to our experimental groups, with a $\mathrm{pH}$ between 7.2 and 7.4. There were four experimental groups ( $n=9$ per group): i) Control (CNT), normal Pi (0.9 mM) and glucose (5.5 mM); ii) HPi, high Pi (2.5 mM) and normal glucose; iii) $\mathrm{HG}$, normal Pi and high glucose (30 mM); and iv) HGHPi: High glucose (30 mM) and high $\mathrm{Pi}(2.5 \mathrm{mM})$.

Quantification of HASMC calcification. HASMCs were grown in six-well plates and treated with growth or calcifying medium. On days 2, 8 and 14 , the culture medium in several six-well plates was removed and washed with PBS, and cells were subsequently treated with $0.6 \mathrm{~N} \mathrm{HCl}$ overnight at $4^{\circ} \mathrm{C}$. Calcium concentration in the supernatant was determined by the o-cresolphthalein complexone method, using a Calcium Assay kit (Nanjing Jiancheng Bioengineering Institute Co., Ltd., Nanjing, China). A Bicinchoninic Acid (BCA) Protein Assay kit (Aspen Biotechnology Co., Ltd., Wuhan, China) was used to evaluate protein concentration, in order to normalize the calcium concentration.

Reverse transcription-quantitative polymerase chain reaction $(R T-q P C R)$. Total RNA was extracted from HASMCs with TRIzol ${ }^{\circledR}$ reagent (Invitrogen; Thermo Fisher Scientific, Inc., Waltham, MA USA), according to the manufacturer's instructions. cDNA was generated using a PrimeScript ${ }^{\mathrm{TM}}$ RT reagent kit with gDNA eraser (Takara Bio, Inc., Otsu, Japan). qPCR was performed on a StepOne ${ }^{\mathrm{TM}}$ Real-Time PCR system (Thermo Fisher Scientific, Inc.) with the SYBR ${ }^{\circledR}$ Premix Ex $\mathrm{Taq}^{\mathrm{TM}}$ reagent kit (Takara Bio, Inc.). The PCR conditions were as follows: $95^{\circ} \mathrm{C}$ initial denaturation for $1 \mathrm{~min}$., 40 cycles with $95^{\circ} \mathrm{C}$ denaturation for $15 \mathrm{sec}, 58^{\circ} \mathrm{C}$ annealing for $20 \mathrm{sec}, 72^{\circ} \mathrm{C}$ elongation for $45 \mathrm{sec}$. The program for analytic melting was followed by an increase in temperature from $60^{\circ} \mathrm{C}$ to $95^{\circ} \mathrm{C}$ with a $0.05^{\circ} \mathrm{C} / \mathrm{sec}$ ramp rate. GAPDH was used as the reference gene. PCR primers were purchased from Genecreate Bioengineering Co., Ltd. (Wuhan, China) and the sequences were as follows: Runx2, 5'-TACTCTGCCGAGCTACGA AATG-3' (forward), 5'-TGAAACTCTTGCCTCGTCCG-3' (reverse); SM22 $\alpha, 5^{\prime}$-ATCCAAGCCAGTGAAGGTGC-3' (forward), 5'-ACTCCCTCTTATGCTCCTGGG-3' (reverse); SM $\alpha$-actin, 5'-GTGACGAGGACGAGACCACC-3' (forward), 5'-GGGTCAGGATACCTCGCTTG-3' (reverse); GAPDH, 5'-CGCTAACATCAAATGGGGTG-3' (forward), 5'-TTG CTGACAATCTTGAGGGAG-3' (reverse). The specificity of the PCR products was confirmed by melting curve analysis. Relative expression levels were determined using the $2^{-\Delta \Delta \mathrm{Cq}}$ method (19).
Western blotting. HASMCs were lysed using radioimmunoprecipitation assay buffer (Aspen Biotechnology Co., Ltd.) and protein concentrations were measured with a BCA protein assay. Total protein (40 $\mu \mathrm{g} /$ lane) was separated by 8 or $10 \%$ SDS-PAGE and transferred to a polyvinylidene difluoride membrane. Following blocking in 5\% non-fat milk in Tris-buffered saline and Tween 20 for $1 \mathrm{~h}$ at room temperature, membranes were incubated with the following primary antibodies overnight at $4^{\circ} \mathrm{C}$ : Rabbit anti-GAPDH (dilution 1:10,000; cat. no. ab37168; Abcam, Cambridge, UK) and rabbit anti-Pit-1 (dilution 1:2,000; cat. no. ab177147; Abcam). Membranes were then incubated with horseradish peroxidase-labeled secondary antibody for $30 \mathrm{~min}$ at room temperature (dilution 1:10,000; cat. no. AS1107; Aspen Biotechnology Co., Ltd.). Immunoreactive proteins were detected using enhanced chemiluminescent reagents (Aspen Biotechnology Co., Ltd.). Quantitative densitometry analysis was performed using AlphaEaseFC software Version 3.3.0 (ProteinSimple, San Jose, CA, USA).

Alizarin red staining. HASMCs in six-well plates were washed three times with PBS and fixed with $10 \%$ (v/v) formaldehyde for $10 \mathrm{~min}$ at room temperature. The slides of cells were subsequently washed with PBS three times. Cells were exposed to $1 \%(\mathrm{w} / \mathrm{v})$ Alizarin red for $30 \mathrm{~min}$ at $37^{\circ} \mathrm{C}$ and then washed with $0.2 \%(\mathrm{v} / \mathrm{v})$ acetic acid. Red indicated positive staining of calcium nodules using a light microscope (Olympus Corporation, Tokyo, Japan; magnification, x200).

Statistical analysis. All numerical data are expressed as the mean \pm standard deviation. The mixed-effects model of repeated measures (MMRM) was used to analyze every parameter. The model included group, time point and group-by-time point interaction as fixed factors. The restricted maximum likelihood (REML) was used. The covariance structure to model the within-sample errors was unstructured. The Kenward-Roger method was used to estimate the denominator degrees of freedom. Type III tests for the least-squares means were used for statistical comparisons. Comparisons between each group at every time point were reported. PROC MIXED in SAS Version 9.2 (SAS Institute, Cary, North Carolina, USA) was used for MMRM. $\mathrm{P}<0.05$ was considered to indicate a statistically significant difference.

\section{Results}

Effects of hyperphosphatemia and hyperglycemia on calcification. To determine the effects of hyperphosphatemia and hyperglycemia on the calcification of cultured HASMCs, Alizarin red staining intensities (Fig. 1A) and Ca concentrations (Fig. 1B) were determined on days 2, 8 and 14. The results revealed that no calcification occurred under normal conditions. Significant calcification was present in hyperphosphatemia or hyperglycemia medium on days 8 and 14, compared with the CNT $(\mathrm{P}<0.01)$, and calcification in HG media was more severe than in HPi media $(\mathrm{P}<0.01)$. When cultured in both hyperphosphatemia and hyperglycemia media, the most severe calcification occurred as early as day 2 compared with CNT, HPi and HG $(\mathrm{P}<0.01)$. 
$\mathbf{A}_{\text {CNT }}$

2 days

8 days
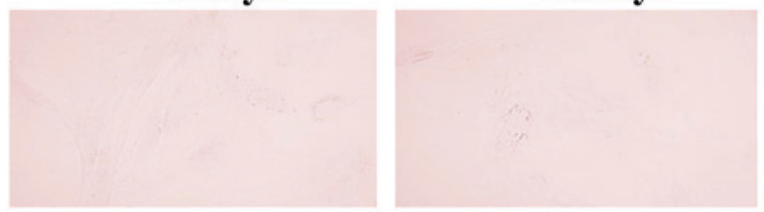

HPi
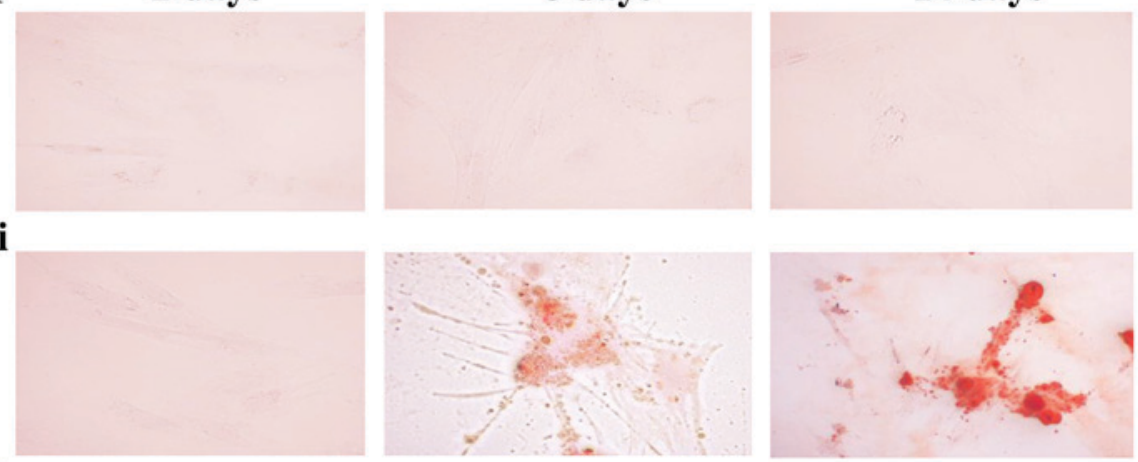

HG
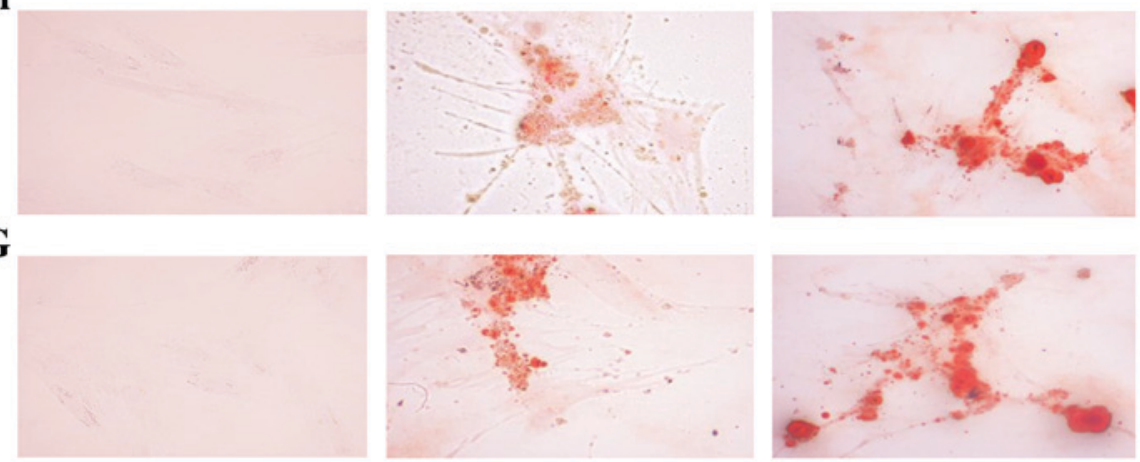

HGHPi
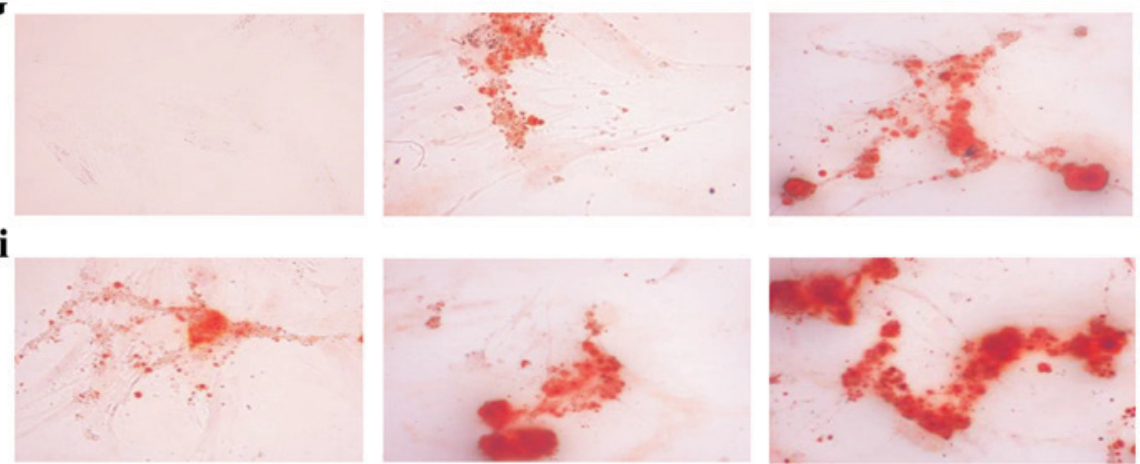

(Original magnification $\times \mathbf{2 0 0}$ )

B

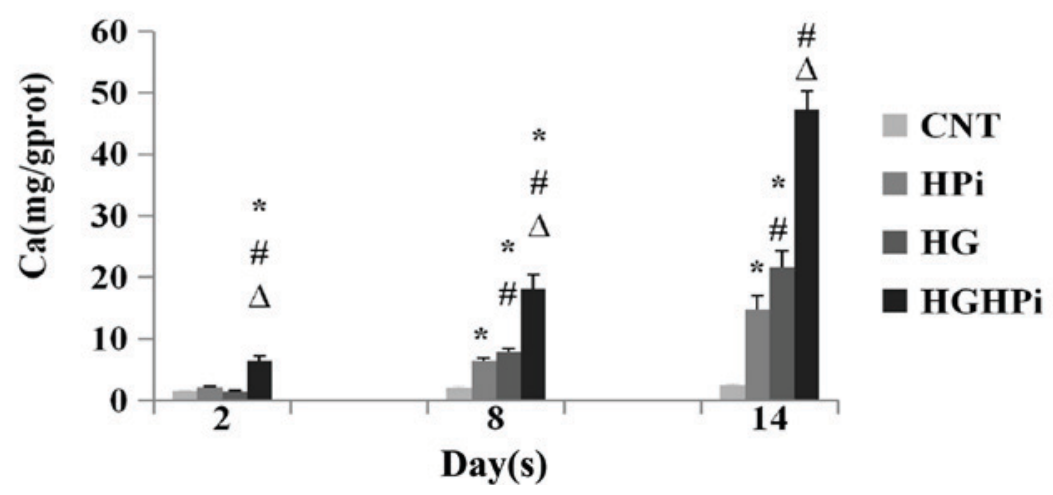

Figure 1. (A) Images of Alizarin red staining sections (original magnification, x200). HASMCs were cultured in Dulbecco's modified Eagle's medium supplemented with CNT (0.9 mM Pi, $5.5 \mathrm{mM}$ glucose), HPi (2.5 mM Pi) and/or HG (30 mM glucose) for 14 days to induce calcification. Sections exhibited no staining when cultured in normal medium, and significant calcification was observed in HPi or HG medium. The most severe calcification was observed in the HGHPi group. (B) Quantification of HASMC calcification induced by HPi and/or HG. Calcium content was normalized to total cellular protein, as determined by a bicinchoninic acid protein assay. The combined effects of hyperphosphatemia and hyperglycemia on HASMC calcification were observed. Values are expressed as the mean \pm standard deviation $(\mathrm{n}=9)$. ${ }^{*} \mathrm{P}<0.01$ vs. CNT; ${ }^{\sharp} \mathrm{P}<0.01$ vs. HPi; ${ }^{\circ} \mathrm{P}<0.01$ vs. HG. HASMC, human aortic smooth muscle cell; Pi, inorganic phosphorus; CNT, control; HPi, high Pi; HG, high glucose; HGHPi, high Pi and glucose.

Thus, it was concluded that there were combined effects of hyperglycemia and hyperphosphatemia on the calcification of HASMCs.

Effects of hyperphosphatemia and hyperglycemia on the expression of Pit-1 proteins. Pit-1 protein expression on day 2, 8 and 14 was detected by western blot analysis (Fig. 2). The results demonstrated that $\mathrm{HPi}$ and $\mathrm{HG}$ elevated the expression of Pit- 1 on days 8 and 14, compared with the $\mathrm{CNT}(\mathrm{P}<0.01)$. The combined effects of hyperphosphatemia and hyperglycemia on Pit-1 expression were also observed: HASMCs cultured in hyperphosphatemia and hyperglycemia medium expressed the most Pit-1 protein from day 2, compared with that in the CNT, $\mathrm{HPi}$ and $\mathrm{HG}$ groups $(\mathrm{P}<0.01)$.
Effects of hyperphosphatemia and hyperglycemia on phenotypic transition. The relative expression of Runx2, SM22 $\alpha$ and SM $\alpha$-actin mRNA in cultured HASMCs was evaluated by RT-qPCR analysis (Fig. 3). Upregulation of Runx2, as well as downregulation of SM22 $\alpha$ and SM $\alpha$-actin was observed in the HPi, HG and HGHPi groups, compared with the CNT. The differences in the expression of SM $22 \alpha$ and Runx 2 mRNAs on day 14 were significant between the HGHPi and HPi or HG groups $(\mathrm{P}<0.01)$. The differences in the expression of SM $\alpha$-actin mRNA on day 14 between the HGHPi and HG groups were not significant $(\mathrm{P}=0.106)$, but both groups exhibited significantly decreased expression compared with the HPi group $(\mathrm{P}<0.01)$. Therefore, it was concluded that there were combined effects of 


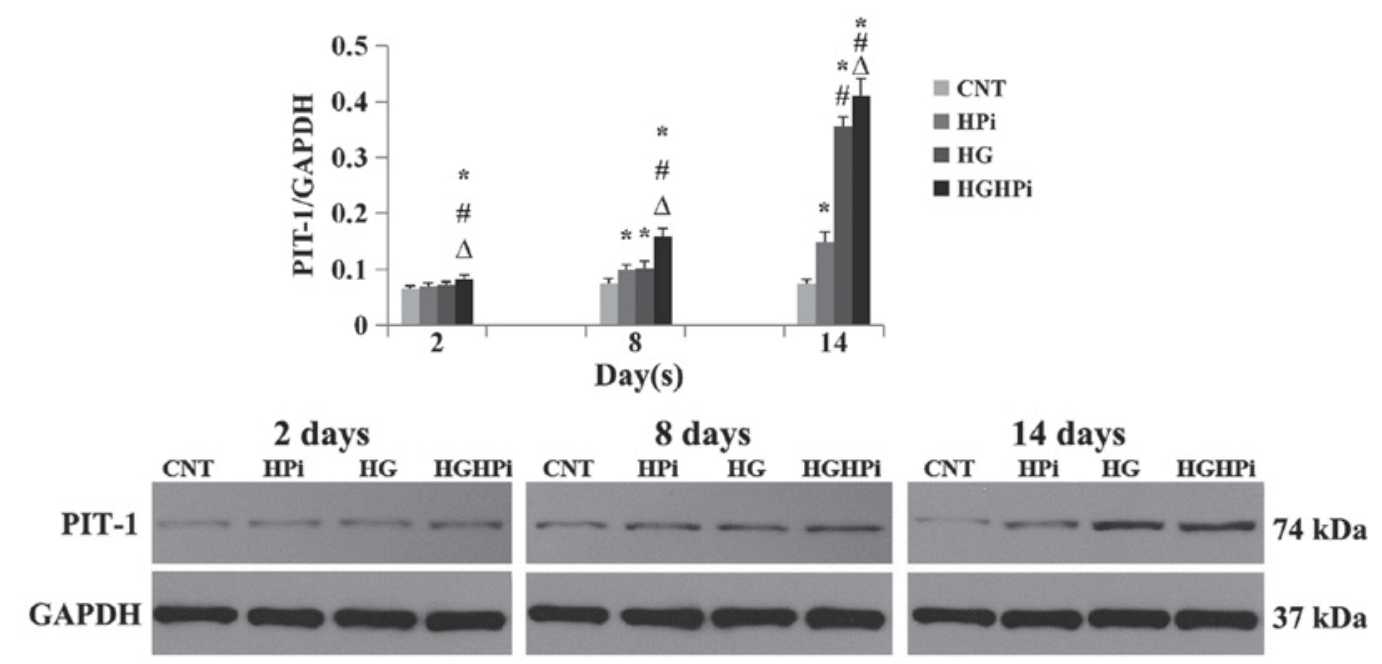

Figure 2. Expression of Pit-1 protein in human aortic smooth muscle cells cultured with normal, HPi and/or HG medium. Pit-1 protein expression was increased by HPi or HG. The combined effects of hyperphosphatemia and hyperglycemia on Pit-1 expression were also observed. Values are expressed as the mean \pm standard deviation $(\mathrm{n}=9) .{ }^{*} \mathrm{P}<0.01$ vs. $\mathrm{CNT} ;{ }^{*} \mathrm{P}<0.01$ vs. $\mathrm{HPi} ;{ }^{4} \mathrm{P}<0.01$ vs. HG. $\mathrm{Pi}$, inorganic phosphorus; $\mathrm{CNT}$, control; $\mathrm{HPi}$, high $\mathrm{Pi} ; \mathrm{HG}$, high glucose; HGHPi, high Pi and glucose.
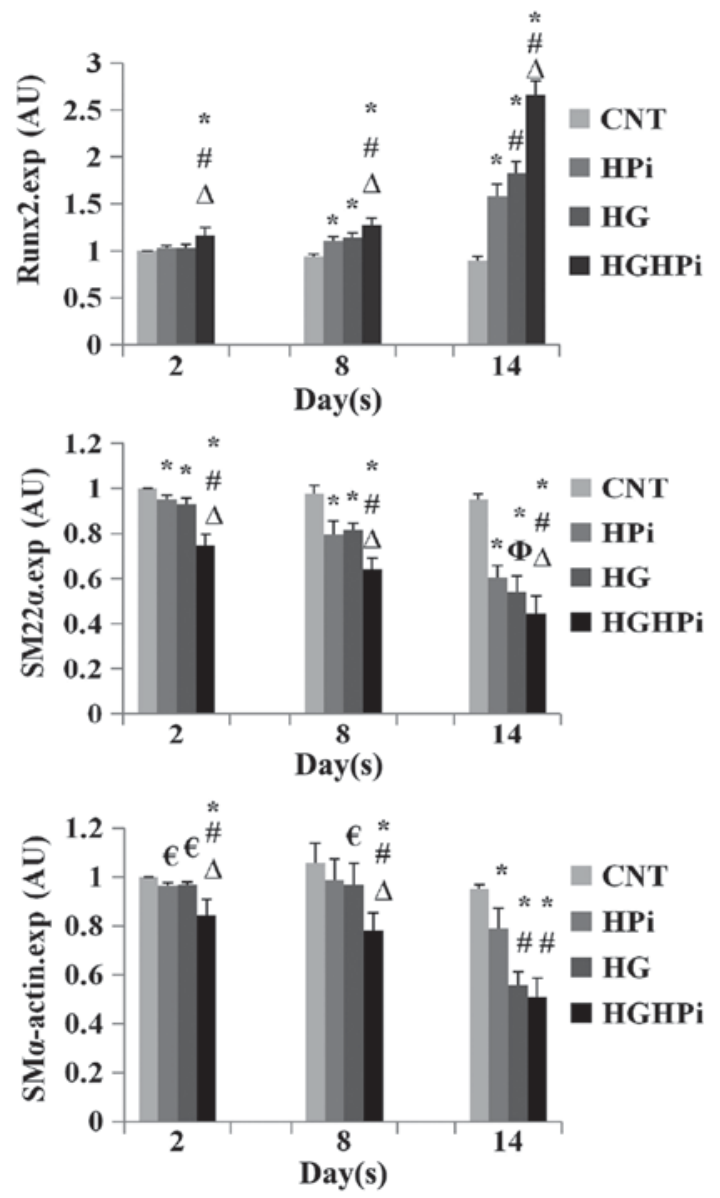

Figure 3. Relative expression of Runx2, SM22 $\alpha$ and SM $\alpha$-actin mRNA of HASMCs cultured in normal, HPi and/or HG medium. Upregulation of Runx 2 and downregulation of SM22 $\alpha$ and SM $\alpha$-actin was observed in the HPi, HG and HGHPi groups. The combined effects of HPi and HG on HASMC phenotypic transition were also observed. Values are expressed as the mean \pm standard deviation $(\mathrm{n}=9) .{ }^{€} \mathrm{P}<0.05$ vs. $\mathrm{CNT}$; ${ }^{*} \mathrm{P}<0.01$ vs. $\mathrm{CNT}$; ${ }^{\Phi} \mathrm{P}<0.05$ vs. $\mathrm{HPi} ;{ }^{\#} \mathrm{P}<0.01$ vs. $\mathrm{HPi} ;{ }^{\Delta} \mathrm{P}<0.01$ vs. HG. AU, arbitrary units; HASMC, human aortic smooth muscle cell; $\mathrm{Pi}$, inorganic phosphorus; CNT, control; HPi, high Pi; HG, high glucose; HGHPi, high Pi and glucose; Runx2, runt-related transcription factor 2; SM22 $\alpha$, smooth muscle $22 \alpha$; SM $\alpha$-actin, smooth muscle $\alpha$-actin. hyperglycemia and hyperphosphatemia on the phenotypic transition of HASMCs from vascular smooth muscle cells to osteoblast-like cells.

\section{Discussion}

Clinically, hyperphosphatemia and hyperglycemia are common comorbidities of patients with CKD. The results of the present study indicated that both hyperphosphatemia and hyperglycemia induced HASMC calcification and the phenotypic transition from vascular smooth muscle cells to osteoblast-like cells. These results are consistent with previous reports $(10,20)$. It is unclear what occurs when hyperphosphatemia and hyperglycemia are present at the same time; however, these are likely to be the conditions that occur in patients with diabetic kidney disease (DKD) (17). It is well established that CKD patients with hyperglycemia have a shorter survival time and/or higher mortality rate $(21,22)$. Yoshida et al $(23)$ incubated rat and human aortic SMCs with various concentrations of phosphate and glucose, and demonstrated that calcium accumulation is increased by high phosphate concentration in a dose-dependent manner, but not by high glucose concentration. However, this was inconsistent with the findings of the present study and others $(9,24)$. The exact reasons for these differences are unclear; they may be due to the complicated mechanisms of $\mathrm{VC}$, or perhaps there were some overlooked details in these previous experiments, which resulted in insufficient induction of VC by hyperglycemia. Rat aortic vascular rings were cultured in hyperphosphatemia and hyperglycemia media in our previous work, and these results also supported the findings of the present study (unpublished data). Hence, it is reasonable to propose that there are combined effects of hyperglycemia and hyperphosphatemia on $\mathrm{VC}$, which may contribute to the mortality of CKD patients with hyperglycemia. The current results provide experimental evidence for this hypothesis and suggest that it would be beneficial to advocate stricter control on the serum phosphorus and glucose levels of patients with DKD. In addition, conditions 
of hyperphosphatemia combined with hyperglycemia should be considered an appropriate experimental model to study VC in DKD.

There are three types of $\mathrm{NaPi}$ cotransporter in humans, and Pit-1 is the predominant type in VSMCs $(15,25)$. In recent decades, an increasing number of studies have demonstrated that Pit-1 regulation serves a significant role in the pathogenesis of VC $(16,26,27)$. The present study suggested that Pit-1 expression was upregulated not only by hyperphosphatemia but also by hyperglycemia, and the level of expression appeared to be associated with $\mathrm{Ca}$ deposition in calcified HASMCs. Hence, Pit-1 may be a promising index for VC.

However, the present study had certain limitations. The model did not represent the structure and/or matrix of a vessel, and HASMCs were cultured in vitro. Thus, the results may differ in vivo. More detailed research, in both animals and clinical trials, will be required in order to verify the underlying mechanisms of and effective control strategies for VC.

In conclusion, it was observed that there were combined effects of hyperphosphatemia and hyperglycemia on HASMC calcification. Hyperphosphatemia medium combined with hyperglycemia medium should be considered an appropriate experimental model to study $\mathrm{VC}$ in DKD. Pit-1 may be a promising index for $\mathrm{VC}$. These findings may aid in making clinical decisions for patients with CKD.

\section{Acknowledgements}

The authors would like to thank Professor Xicheng Hong for assistance in examining the data.

\section{Funding}

Not applicable.

\section{Availability of data and materials}

All data generated and analyzed during the current study are available from the corresponding author on reasonable request.

\section{Authors' contributions}

All authors conceived and designed the research. PW and PZ performed the experiments and drafted the manuscript. DP analyzed the data and revised the manuscript. WC reviewed the manuscript. All authors read and approved the final manuscript.

\section{Ethics approval and consent to participate}

Not applicable.

\section{Patient consent for publication}

Not applicable.

\section{Competing interests}

The authors declare that they have no competing interests.

\section{References}

1. Górriz JL, Molina P, Cerverón MJ, Vila R, Bover J, Nieto J, Barril G, Martínez-Castelao A, Fernández E, Escudero V, et al: Vascular calcification in patients with nondialysis CKD over 3 years. Clin J Am Soc Nephrol 10: 654-666, 2015.

2. Emerging Risk Factors Collaboration; Sarwar N, Gao P, Seshasai SR, Gobin R, Kaptoge S, Di Angelantonio E, Ingelsson E, Lawlor DA, Selvin E, et al: Diabetes mellitus, fasting blood glucose concentration, and risk of vascular disease: A collaborative meta-analysis of 102 prospective studies. Lancet 375: 2215-2222, 2010.

3. London GM, Guérin AP, Marchais SJ, Métivier F, Pannier B and Adda H: Arterial media calcification in end-stage renal disease: Impact on all-cause and cardiovascular mortality. Nephrol Dial Transplant 18: 1731-1740, 2003.

4. Mizobuchi M, Tower D and Slatopolsky E: Vascular calcification: The killer of patients with chronic kidney disease. J Am Soc Nephrol 20: 1453-1464, 2009

5. Hruska K, Mathew S, Lund R, Qiu P and Pratt R: Hyperphosphatemia of chronic kidney disease. Kidney Int 74: 148-157, 2008

6. Demer L and Tintut Y: Vascular calcification: Pathobiology of a multifaceted disease. Circulation 117: 2938-2948, 2008.

7. Giachelli CM: Vascular calcification mechanisms. J Am Soc Nephrol 15: 2959-2964, 2004.

8. Zhan JK, Tan P, Wang YJ, Wang Y, He JY, Tang ZY, Huang W and Liu YS: Exenatide can inhibit calcification of human VSMCs through the NF-kappaB/RANKL signaling pathway. Cardiovasc Diabetol 13: 153, 2014.

9. Liu F, Zhong H, Liang JY, Fu P, Luo ZJ, Zhou L, Gou R and Huang J: Effect of high glucose levels on the calcification of vascular smooth muscle cells by inducing osteoblastic differentiation and intracellular calcium deposition via BMP-2/Cbf $\alpha-1$ pathway. J Zhejiang Univ Sci B 11: 905-911, 2010.

10. Steitz SA, Speer MY, Curinga G, Yang HY, Haynes P, Aebersold R, Schinke T, Karsenty G and Giachelli CM: Smooth muscle cell phenotypic transition associated with calcification: Upregulation of Cbfal and downregulation of smooth muscle lineage markers. Circ Res 89: 1147-1154, 2001.

11. Speer MY, Li X, Hiremath PG and Giachelli CM: Runx2/Cbf $\alpha 1$, but not loss of myocardin, is required for smooth muscle cell lineage reprogramming toward osteochondrogenesis. J Cell Biochem 110: 935-947, 2010.

12. Zhang J,Zheng B,Zhou PP, Zhang RN,He M, Yang Z and Wen JK: Vascular calcification is coupled with phenotypic conversion of vascular smooth muscle cells through Klf5-mediated transactivation of the Runx2 promoter. Biosci Rep 34: e00148, 2014.

13. Li X, Yang H and Giachelli CM: Role of the sodium-dependent phosphate cotransporter, Pit-1, in vascular smooth muscle cell calcification. Circ Res 98: 905-912, 2006.

14. Villa-Bellosta R, Levi M and Sorribas V: Vascular smooth muscle cell calcification and SLC20 inorganic phosphate transporters: Effects of PDGF, TNF-alpha, and Pi. Pflugers Arch 458: 1151-1161, 2009.

15. Lau WL, Festing MH and Giachelli CM: Phosphate and vascular calcification: Emerging role of the sodium-dependent phosphate co-transporter Pit-1. Thromb Haemost 104: 464-470, 2010.

16. Yang H, Curinga $\mathrm{G}$ and Giachelli CM: Elevated extracellular calcium levels induce smooth muscle cell matrix mineralization in vitro. Kidney Int 66: 2293-2299, 2004.

17. Kidney Disease: Improving Global Outcomes (KDIGO) CKD Work Group: KDIGO 2012 clinical practice guideline for the evaluation and management of chronic kidney disease. Kidney Int (Suppl 3): S1-S150, 2013.

18. Yokozawa T, Zheng PD, Oura H and Koizumi F: Animal model of adenine-induced chronic renal failure in rats. Nephron 44: 230-234, 1986

19. Livak KJ and Schmittgen TD: Analysis of relative gene expression data using real-time quantitative PCR and the 2(-Delta Delta C(T)) method. Methods 25: 402-408, 2001.

20. Yoshida T, Yamashita M and Hayashi M: Kruppel-like factor 4 contributes to high phosphate-induced phenotypic switching of vascular smooth muscle cells into osteogenic cells. J Biol Chem 287: 25706-25714, 2012.

21. Jardine MJ, Hata J, Woodward M, Perkovic V, Ninomiya T, Arima H, Zoungas S, Cass A, Patel A, Marre M, et al: Prediction of kidney-related outcomes in patients with type 2 diabetes. Am J Kidney Dis 60: 770-778, 2012. 
22. Wan EYF, Fong DYT, Fung CSC, Yu EYT, Chin WY, Chan AKC and Lam CLK: Prediction of new onset of end stage renal disease in Chinese patients with type 2 diabetes mellitus-a population-based retrospective cohort study. BMC Nephrol 18: 257,2017

23. Yoshida T, Yamashita M, Horimai C and Hayashi M: High glucose concentration does not modulate the formation of arterial medial calcification in experimental uremic rats. J Vasc Res 50: 512-520, 2013.

24. Chen NX, Duan D, O'Neill KD and Moe SM: High glucose increases the expression of Cbfa1 and BMP-2 and enhances the calcification of vascular smooth muscle cells. Nephrol Dial Transplant 21: 3435-3442, 2006.
25. Miyamoto K, Haito-sugino S, Kuwahara S, Ohi A, Nomura K, Ito M, Kuwahata M, Kido S, Tatsumi S, Kaneko I and Segawa H: Sodium-dependent phosphate cotransporters: Lessons from gene knockout and mutation studies. J Pharm Sci 100: 3719-3730, 2011. 26. Suzuki A, Ghayor C, Guicheux J, Magne D, Quillard S, Kakita A, Ono Y, Miura Y, Oiso Y, Itoh M and Caverzasio J: Enhanced expression of the inorganic phosphate transporter Pit-1 is involved in BMP-2-induced matrix mineralization in osteoblast-like cells. J Bone Miner Res 21: 674-683, 2006.

27. Voelkl J, Alesutan I, Leibrock CB, Quintanilla-Martinez L, Kuhn V, Feger M, Mia S, Ahmed MS, Rosenblatt KP, Kuro-O M and Lang F: Spironolactone ameliorates PIT1-dependent vascular osteoinduction in klotho-hypomorphic mice. J Clin Invest 123: 812-822, 2013. 